\title{
Entrevista a Bárbara Colio
}

\section{Regan Postma}

Bárbara Colio, dramaturga mexicana contemporánea, es una de las más conocidas y celebradas del país. Sus obras, entre muchas otras, incluyen: Pequeñas certezas (2007), Usted está aqui (2010), Cuerdas (2010), A propósito de Alicia (2011) y El día más violento (2011). Además de frecuentes representaciones escénicas en México, se han montado sus obras internacionalmente en España, Francia, Argentina, Perú, Inglaterra y los Estados Unidos. Sus premios recientes incluyen el Premio Nacional Víctor Hugo Rascón Banda y el Premio a la Mejor Obra Periodística (Usted está aqui) y el Premio Nacional de Dramaturgia Bellas Artes-Baja California (Cuerdas). La presente entrevista tomó lugar en su casa en la Ciudad de México en agosto del 2010. ${ }^{1}$ La dramaturga respondió a las últimas preguntas posteriormente por email en febrero del 2012.

¿Me podrías contar algo sobre tu juventud y tu formación profesional?

Bueno, yo nací en Mexicali, Baja California que es una ciudad fronteriza y allí pasé toda mi infancia, adolescencia, juventud. Es que realmente mi formación profesional universitaria pasó dentro de una facultad de ingeniería. Estudié licenciatura en sistemas computacionales y administrativos porque siempre desde la primaria, secundaria y prepa para mí las matemáticas siempre fueron algo que me gustó y me parecían muy fáciles. Entonces a la hora de escoger una carrera, aunque siempre me gustó el arte, no había opciones de formación artística en Mexicali-ninguna o sea no era opción. Bueno, entré y me costó muy poco tiempo darme cuenta de que realmente no quería hacer esto con el resto de mi vida. Tenía una romántica idea de lo que era la ingeniería. Pensaba que allí se podía crear cosas con los números y las fórmulas o las ecuaciones. Pero era una idea romántica porque en la realidad estas carreras sirven para trabajar en empresas transnacionales donde 
no hay espacio para la creatividad sino para la productividad. Entonces bueno, al azar que empecé la universidad de inmediato me metí al grupo de teatro que manejaba la misma Universidad Autónoma de Baja California y dos de los cuatro años que cursé en la carrera estuve en un grupo de teatro donde actuaba. Entonces fue una de las veces que me subí al escenario de manera profesional. Conocí también varios estados de la República en los giros que hacíamos y conocí a mucha gente también que se dedicaba a muchas cosas como el arte teatral.

\section{¿Qué te atrajo al teatro, en vez de otro arte, como actriz y dramaturga?}

Ésta es la gran pregunta, ¿no? Yo tuve un acercamiento para el teatro desde muy niña porque mi hermana, la mayor, vivía aquí en el Distrito Federal y entonces cada verano mi mamá y yo veníamos de vacaciones al D.F. a verla. Los veranos es lluvia, entonces para mí los veranos era lluvia e ir al teatro. Afortunadamente a mi hermana y a mi madre les gusta mucho ir al teatro. Siempre iban, es decir siempre nos aventábamos cada verano. Yo era niña de cinco años, seis, siete, ocho y no era de que me llevaron a mí al teatro a ver obras infantiles. De hecho yo de niña nunca vi obras infantiles; eran las obras que ellas querían ver y me llevaban a mí. Entonces yo de niña vi obras como Hécuba, Un tranvía llamado deseo o sea mis referentes teatrales eran absolutamente un teatro para adultos. Entonces para mí era algo muy natural el teatro. Era algo que era parte de mi vida o sea, no conocí a gente que no le gustara. Pensaba que a todo el mundo le debe de gustar al verlo. Cuando regresaba a Mexicali después de mis vacaciones me daba cuenta que a mucha gente no le gustaba o nunca había visto el teatro porque hay muy poca actividad teatral en Mexicali. Sí había, pero muy, muy poca.

Bueno, durante mi infancia y adolescencia también tuve muchas clases de música, de guitarra, de piano que me gustaban bastante. Me gusta hasta la fecha dibujar. Siempre me llamó atención pero no había dónde hacerlo hasta que entré en la universidad y había este grupo de teatro. Me gusta el teatro porque allí, me doy cuenta que allí podía hacer todo lo que me gustaba. Allí tiene que ver con la música, tiene que ver con la estética, con el dibujo, con el cine que siempre me había gustado mucho. Siempre he sido cinéfila. Allí se podía hacer todo. Yo empecé actuando pero sí llegó un momento... porque esto es lo más fácil, ¿no? Cuando entras en un grupo nuevo es lo que haces, es actuar. O sea, para mí la dramaturgia fue algo para la gente viejita y calva y con bastón y con barba porque éstos eran los dramaturgos mexicanos en aquel entonces. Pero entonces la actuación no me dejaba completamente 
satisfecha. Sí, era algo que me gustaba pero había algo que no terminaba allí de agradarme y entonces después de la actuación empecé a dirigir los espectáculos propios con obras de otros autores. Y llegó un momento en que me fui a Tijuana a hacer un diplomado de teatro como a los 25, 26, algo así. También era de actuación y tal y di una clase de dramaturgia por curiosidad y me pidió escribir mi primer texto como tarea. Lo hice, lo entregué. Al maestro le gustó y desde allí lo que hago es escribir. Allí me di cuenta de que la dramaturgia era algo que yo realmente quería hacer dentro del teatro. A mí es lo que más me llena y lo que más me satisface. Sí, es una cuestión de poder. Es una cuestión de decisión, de creación absoluta y en total-libertad. Creo que dentro del teatro el más libre es el dramaturgo.

¿Cómo te afectó la mudanza de la frontera norte al D.F. en cuanto a tu producción dramática?

Súper enriquecedora. Muy enriquecedora. Dura en la vida pero a la vez de un crecimiento personal muy grande. De hecho antes de venirme a vivir al D.F. viví dos años en Tijuana, los cuales disfruté muchísimo porque Tijuana en aquel entonces, en la década de los 90, era una ciudad muy fértil para el teatro. Toda la gente hacía, montaba en casas, en cafés o donde fuera. Mis primeros textos, de verdad, los escribía y a las dos semanas los estaba estrenando. ¿Como quién sabe? Pero allí estaba la gente. Allí se hacían las cosas, o sea era un gran taller, un gran laboratorio Tijuana.

Después de vivir en Tijuana, me fui a vivir a Madrid, España, también un año en una búsqueda de estudios especializados en dramaturgia y también la cuestión de conocer el teatro europeo incluso conocer el teatro sudamericano que realmente lo conocí allá. No lo conocí aquí en México. Fue muy enriquecedor y todas estas experiencias: la residencia que tuve en Londres dos meses, de poder trabajar con dramaturgos de todo el mundo. Todas estas experiencias, en Nueva York, también de dos meses, todos estos cambios geográficos fueron sumándole mucho a mi vida personal y por ende a mi dramaturgia - ha afectado los puntos de vista que tengo sobre el mundo que es finalmente de lo que escribo.

Cuando vengo a vivir al D.F., no era absolutamente consciente al final si me iba a quedar aquí o nada más por una temporada pero las cosas se fueron dando de tal manera que fui apostando a quedarme acá más tiempo. $\mathrm{Y}$ yo lo noto mucho en mi dramaturgia este enfrentamiento con vivir en una ciudad como ésta. Afecta también mucho y creo que algo muy claro en Usted está aquí es que hago una cuestión muy citadina, muy del Distrito 
Federal pero también conservo esta cuestión de fuera. Soy turista de alguna forma. Conservo este punto de vista que es como el de fuera que puede ver ciertas cosas que alguien que ya esté imbuido aquí. Yo veo que este cambio de residencia, como todos los viajes que he hecho, ha sido verdaderamente mi verdadera escuela.

\section{¿Entonces te consideras dramaturga del D.F. o de la frontera norte?}

Esta pregunta siempre les preocupa mucho a los investigadores, pero la neta es de que a mí lo fronteriza no me lo va a quitar nadie. Yo viví en una frontera donde, la verdad, no veía la frontera. Mi casa, es decir la casa de mis padres, está a dos o tres cuadras de la línea. Para mí ir y venir a los Estados Unidos no eran grandes cosas. No sé, el cambiar de idioma, el cambiar de moneda, el ver que hay otras vidas diferentes, otras leyes incluso bajo que estas vidas se rigen o sea como algo muy natural y esto permea tu manera de ser. Yo no sé de verdad si soy del norte, del sur, del centro, del este o del oeste. Yo me considero una dramaturga mexicana y más mexicana en una amplia extensión porque conozco mi país. He vivido en el norte, vivo en el centro, pero también conozco el sur. Antes de irme a otro país, me dediqué a conocer el propio. Entonces yo soy una dramaturga mexicana, de tal pertenencia ya es otra historia.

Tu obra parece tener una variedad de influencias desde la vida cotidiana en Pequeñas certezas hasta los acontecimientos actuales y la mitología griega en Usted está aquí. ¿Podrías hablar acerca de estas u otras influencias mayores?

Últimamente, y lo platicaba con otro dramaturgo que ha estado viendo mis obras últimas, hay una gran tendencia de escribir sobre historias familiares. Finalmente Pequeñas certezas es una historia de hermanos y de nuevas familias que se crean aquellas por decisión y no por haber nacido en ellas. Cuerdas es una historia de tres hermanos. Usted está aquí también es una historia de familia, absolutamente, una madre con un hijo y dos hermanas. En El día más violento, que es la obra que se va a estrenar el 23 de noviembre [2010] con la Compañía Nacional de Teatro, que también es una obra que dentro del contexto revolucionario, al principios de la Revolución, el eje central son los hermanos, Aquiles y Carmen Serdán. Entonces lo hago inconciente, o sea no es una cosa que yo pretenda hacer una apología sobre las relaciones familiares, pero de pronto encuentro en ellas la mayor complejidad. Seres que aparentemente podrían compartir la misma genética, que aparentemente podrían compartir la misma forma de ver el mundo. Sin embargo son seres tan 
ajenos, tan diferentes, tan distantes. De alguna forma caigo, últimamente he caído en esas historias que son cotidianas, en historias donde los personajes no sufren grandes cambios sino pasan a otra etapa de su existencia. Creo que de pronto esto es lo más doloroso dentro de la vida. En Usted está aquí, que sí fue un ejercicio formal que yo me propuse hacer, es otro tipo de historia, otro tipo de aliento pero que no deja de tener esto de la familia.

Te felicito por el Premio Nacional Víctor Hugo Rascón Banda que ganaste con Usted está aquí. ¿Por qué escribiste esta obra?

Fue inevitable. Yo lo quería evitar pero fue inevitable. Todas las obras que escribo empiezan de una misma manera. Me entero de algo, conozco algo, pienso sobre algo que en ese momento me afecta o me turba o me molesta o me apasiona. Es algo en que siempre estoy pensando y trato de explicármelo y no encuentro explicación o razón suficiente o respuesta suficiente. Entonces empiezo a obsesionarme tanto que termino escribiendo una obra.

En Usted está aquí lo que realmente me empujo a esta obra fue el caso específico de Isabel Miranda de Wallace que fue una mujer que secuestran a su hijo y no encuentra respuestas de las autoridades; decide hacer ella misma la búsqueda. Entonces me ha llamado la atención viviendo en esta ciudad de tanto andar por las calles y ver todo lo espectacular que esta mujer ponía y cómo ella fue haciendo cosas y demás. Entonces comencé a admirarla a ella y la pregunta era: “¿Yo haría lo mismo?” ¿En qué radica el que no es la primera ni desgraciadamente es la última en llevar sufrir una pérdida así o va a tener un problema así no solamente en México sino en toda Latinoamérica? Pero no todos reaccionan como ella: mucha gente desespera, mucha gente se va a la iglesia a rezar, mucha gente se da un tiro, mucha gente cobra venganza. Todas las reacciones son posibles y sin embargo esta mujer, además de avanzar en su propio caso, ayuda los casos de los demás.

Esto me hacía pensar mucho en el heroísmo, en esta cuestión de los héroes que ya parece que no existen ahora hoy en día. En esta sociedad está fuera de moda completamente que haya héroes. No hay porque: ¿Qué es el heroísmo? ¿En qué consiste? En alguien que lucha por una convicción, que lucha por algo, que ya es una convicción que casi parece obsesión, locura y que no la abandona. Sin embargo escuché muchas conversaciones donde esta mujer no le causaba admiración a todos sino que mucha gente la acusaba de loca, de que nada más quería publicidad, de que estaba ganando dinero con el caso del hijo. Toda esta especulación, de la cual yo no sé qué es cierta o no, no tengo la menor idea, me llevaba a esto: ¿En qué momento nos perdimos esta 
noción del héroe? ¿Ya los héroes son tan necios? ¿Qué tanta locura hay en un héroe? Porque finalmente los héroes son los que dan su vida por una causa y me pregunto: ¿En esta época hay alguien que dé la vida por una causa? En esta época de desilusión, de apatía donde los ideales ya fueron aniquilados desde mucho tiempo, donde sabemos que no si protestamos vamos a lograr algo porque no se va a lograr nada.

Entonces todo este pensamiento me llevaba a escribir esta obra; inevitablemente me llevó a Antígona. No pude evitarlo. De hecho lo quise evitar pero me llevaba a la resolución de que no me basaba en el mito de Antígona. Es como un eco o simplemente como un espejo. Es como verse a través de este espejo para realmente hablar de lo que estamos experimentando aquí en muchas ciudades más. Porque es una obra muy peligrosa. Temía mucho. Temo mucho porque hay muchas obras que denuncian los temas de la pobreza, las matanzas, los secuestros, de todo esto, pero son muchas obras que a mí me caen un poco mal porque denuncian, son panfletarias, dicen, pero la verdad: ¿Qué hacemos nosotros al respeto de esto? Me costaba pudor como un respeto a la gente que sufre este tipo de cosas entonces. El gran asunto de la obra es estamos aquí pero tampoco nos importa tanto como para hacer algo para que cambie. Es una obra que me causa mucho respeto el tema pero también es una obra muy peligrosa.

En Usted está aquí hay bastante interacción entre los actores y el público especialmente al final cuando Ana sale del escenario y camina por el público. ¿Qué relación buscas entre la obra y los espectadores?

Mi relación con el espectador es de que finalmente uno escribe una obra que va a ser representada escénicamente y va a ser escuchada, vista y sentida por un público. Entonces en el momento de escribir pienso en el sentido cómplice del juego porque una obra de teatro es un juego que yo estoy planteando y tengo que invitar a él que me ve. No porque esté sentado en la butaca tiene la obligación de seguir jugando conmigo. Se puede levantar y se puede ir. Entonces es plantear un juego y también dar al otro jugador sus elementos para que siga conmigo.

En el caso específico de Usted está aquí tiene que ver todo hasta con el título y el montaje también lleva este título a un nivel más extremo. En el montaje los espectadores estaban sentados en el lugar mismo donde sucedía la acción. Entones era con el propósito de "vamos, la obra no está sucediendo allá y yo estoy aquí protegida en las butacas en lo oscuro sino yo estoy aquí a vistas de todos los demás que están y me están viendo igual 
que los actores. No tengo a dónde irme". Cuando sucede el rompimiento del final es donde los actores se pasan, digamos al nivel del público, finalmente están imbuidos en una situación social y tampoco les está importando mucho. Allí sí, es un acercamiento a propósito con el espectador —el hacerlo sentir que usted está aquí.

¿Deseas provocar un cambio político o social con el teatro? ¿Buscas este cambio en los espectadores?

No lo sé de cierto. Acabo de leer una crítica hace poco que hizo Bruno Bert de Usted está aquí donde decía que mi trayectoria de obras y tal se atisbaba una cuestión de teatro con una preocupación por lo social. Para mí fue muy revelador porque también poco estaba consciente de esto. Pero realmente no soy... vamos, todo teatro es político. Partamos de eso. Todo teatro. Es de la representación de un pueblo y el pueblo es el polis. Todo el teatro es político. Todo teatro causa una reacción porque es un reflejo de la sociedad en la que vivimos. Partiendo de allí, podría ser político pero no pretendo gran cosa.

Hubo una experiencia en una función de Usted está aquí. Yo estaba un poco fuera, estaba fuera de la representación. Estaba tomando video precisamente. Creo que la obra tenía unos 20 minutos de haber empezado y una señora en el público empezó a llorar de una forma fuerte. La señora se le movió algo allí muy fuerte tanto que uno de los actores, que hace Rodrigo Murray, se le acercó en plena función y la tocó y preguntó “¿Está usted bien? ¿Puedes seguir?" Ella dijo "sí” y siguieron. Fue una función muy cargada, muy cargada porque todos empezamos a sentir... decían: "Puta madre. ¿Qué estamos haciendo? ¿Por qué hacemos llorar a esta señora?” Fue una función muy, muy especial. Yo estaba grabando el video y dejé de grabar. Fue algo que me dio pudor. Dije: "No, voy a hacer obras divertidas. ¿Por qué escribo estas cosas?" Bueno, para la señora fue una cuestión muy catártica. Yo no sé lo que le haya pasado pero luego alcancé escuchar después. Ella había tenido una experiencia similar de secuestro de un ser querido pero ella pensaba que lo tenía superado, que lo había dejado en el pasado. Pero en este momento se dio cuenta que no lo había dejado en el pasado sino que lo había suprimido de su vida y allí se le vino muy cabrón la reacción.

Estos son momentos en el teatro en los que tú cobras mucha conciencia de tu labor como dramaturgo. ¿Qué es lo que expones en la escena? ¿Qué es lo que muestras tanto de ti mismo? ¿Qué es lo que avientas a un espectador a que le puedes causar como este tipo de cosa? Rodrigo Murray 
lo dijo muy bien después de esa función. Platicamos todos después como estábamos muy movidos por esta función. Dijo, "haber hecho esta obra, todo por lo que hemos pasado por hacer esta obra, valió la pena por esta función". Esto es más que político, es una cuestión como humana.

¿Podrías comentar las puestas de escena de tus obras en otros países-Inglaterra, España, Perú, Estados Unidos? ¿Cómo ha sido la recepción en comparación con la recepción en México?

Sé poco de las que he visto, más que nada con Pequeñas certezas que es la que se montó varias veces. Debo señalar la importancia que tienen las publicaciones de tus obras de teatro, lo importante que es publicar tus obras, traducirlas porque todos estos montajes han sido generados por gente que se encuentra el libro en una librería de teatro, leen la obra, les gusta y la montan. Así ha sido. No ha sido proyecto binacional. Nada. Sí, hay gente que de pronto me habla y me dice, encontré tu obra y la quiero montar y va.

La experiencia que tuve más cercana fue el montaje que hizo en Perú Alberto Ísola. Es un gran director de Perú y un gran amigo además. Fue preciosa la temporada de Pequeñas certezas y mucha gente me preguntaba si en Perú se iba a adaptar porque en Pequeñas certezas originalmente la acción sucede entre el D.F. y Tijuana. Entonces si se montara en otro país, pues dicen que se adaptara porque quién iba a saber dónde está el D.F. y dónde está Tijuana. ¿Pero cuándo a Shakespeare con sus distancias se cambia? O incluso con los argentinos, los españoles, los gringos cuando se montan no se cambia New York por Puebla. Sigue siendo New York. Digo bueno, va a seguir siendo Tijuana y va a seguir siendo México porque lo que importa no son las ciudades sino la relación que hay entre una ciudad central y una ciudad periférica y esto en todo país existe.

Entonces la recepción que tuvo fue muy buena; la obra gustó mucho. El acercamiento que tuvo Alberto Ísola a la obra fue muy bueno. En Inglaterra, en Gales, fue otra versión completamente distinta donde todo sucedía como en un set de fotografía. Porque ellos a lo que más les llegó fue esta cuestión de que yo divido la obra en fotos. Cosa que en los demás montajes había estado una manera sutil pero para ellos fue el eje rector del montaje. Todos los muebles son formados con elementos de fotografía. Entonces eso estuvo padre. En Los Ángeles no vi realmente nada. No supe cómo lo hicieron. Hice una lectura en Chicago también y también entró perfectamente a esta cultura. Porque finalmente creo que esta obra habla de las relaciones entre los hermanos y cómo la gente se inserta en familias nuevas y también 
de esta soledad que hay que hace que nos enganchemos a los primeros que nos invitan a comer a su casa.

¿Cuáles han sido tus experiencias durante este último año con Usted está aquí y tus otras obras teatrales recientes?

Usted está aquí fue traducida al francés por Catherine Marnas y presentada como lectura dramatizada por la Compañía PARNAS en Francia. En Marsella, se realizó el evento "Un jour fait sur Mexico" donde se estrenó la lectura. Luego se presentó en la ciudad de Bayonne en el Festival Translatines 2011 y entonces tuvo una tercera presentación en el Teatro Nacional de Strasbourg. Estuve presente en las dos últimas. Al final había un espacio para conversar con el público. El texto fue muy bien recibido e interesó mucho el discurso comparado entre la imagen de Antígona y la realidad contemporánea latinoamericana. Esto fue ayudado, claro, por la excelente traducción y dirección que Catherine Marnas realizó. Fue una experiencia realmente emocionante el enfrentar el texto en otro idioma y ante un publico muy distinto y constatar su efectividad, la fuerza con la que atrapa al espectador.

Cuerdas también tuvo lo suyo, ya que fue invitada al Festival Voces del Mundo en Madrid, España, donde se realizó una lectura dramatizada dirigida por Fefa Noia. La obra gustó mucho, creo que dado a su tema y más que nada a su estructura de lenguaje no se sintió como un texto lejano a la sonoridad española. Cuerdas fue presentada también en Argentina, en el Festival Cumbre de las Américas en Mar del Plata que disfruté mucho y donde el montaje obtuvo dos menciones especiales.

Por lo que ves, en estos últimos meses he tenido la fortuna de experimentar el efecto de mis textos en tres países, ante públicos muy distintos, y aprender, siempre aprender.

\section{¿En qué trabajas ahora? ¿Cuál es tu próximo proyecto?}

He terminado un nuevo texto que fui armando en los últimos meses del año pasado mientras me encontraba de viaje entre España y Francia. Es un texto algo inquietante que me entusiasma mucho. Y que me gustaría mucho ver pronto en escena. También estoy trabajando otro texto, pensado para estrenarlo en Lima, Perú con el director Alberto Ísola, con el que ya tuve la grata experiencia de que dirigiera Pequeñas certezas en aquel país en 2009. 


\section{Notas}

1 Quisiera reconocer la Fundación Tinker por los fondos para realizar este proyecto. También me gustaría agradecer a Bárbara por su generosidad e interés en esta entrevista y a mi colega Elizabeth Villalobos por presentarnos. 